\title{
The Effect of Electronic Writing Tools on Business Writing Proficiency
}

\author{
Lisa Walters and Susan McNamara
}

Lisa M. Walters is Visiting Assistant Professor of Business Administration and Susan McNamara is Assistant Professor of Business Administration, School of Business, State University of New York at Fredonia.

\begin{abstract}
Digital applications are increasingly being used in the classroom, and this exploratory study, which involved two sections of a business communications course, focuses on the use of digital tools to improve business writing. In one section, the professor used traditional pedagogy. In the other section, another professor used traditional pedagogy augmented with two digital business writing applications. As assessed by the university's approved rubric for writing, the students whose learning included the augmented digital tools demonstrated greater improvement in their business writing than did students who experienced traditional business writing instruction. Based on the findings, it was recommended that future research should determine the reliability of the rubric prior to its use as well as minimize professor variation by having the same professor teach both sections.
\end{abstract}


Keywords: electronic writing tools, writing, proficiency

DOI: http://dx.doi.org/10.15239/j.brcadvje.2014.02.01.ja01

\section{INTRODUCTION}

The objectives for business communications classes at the State University of New York at Fredonia (SUNY Fredonia) are for students to (a) demonstrate the ability to use clear, concise oral and written language; (b) write a professional memorandum; (c) compose business cover letters that use style and tone appropriate to the subject, purpose, and audience; (d) create a professional resume; (e) develop bibliographies and use citations appropriately; (f) understand how to produce professional business-style reports; (g) generate cohesive speech outlines and speech notes; (h) develop and/or improve ability to select, organize, and effectively deliver information in an ethical, businesslike manner for a diverse public audience; (i) use appropriate language, articulation, nonverbal communication, and visual supporting materials for public speaking; $(j)$ recognize self-communication tendencies as well as those of diverse or intercultural audiences; $(\mathrm{k})$ recognize how to communicate in a problemsolving group setting; and (l) demonstrate essential critical listening, conflict management, time management, and problem-solving skills.

In these objectives, the emphasis on writing is clear, with half of the stated objectives explicitly identifying some aspect of effective writing as an outcome. Teaching writing can be challenging, and many students find writing to be a labor-intensive activity. Professors also experience such labor intensiveness, as their evaluation of writing is typically ongoing; they review not only initial submissions but numerous revisions as well. To address the challenges of teaching writing and to better meet these objectives, the faculty in business communications are looking for a better way to teach business writing. 
At SUNY Fredonia, there are generally 30 to 40 students in a business communications class, which is considered a large class. Arias and Walker (2004) found a negative relationship between the size of the class and student performance, as measured by exam point totals. Further, based on a survey on course section choice, they found that students are more likely to choose and attend regularly classes in which the professor knows them and in which they feel more comfortable asking and answering questions. Such conditions are generally found in smaller classes. With large business communication classes, the faculty at SUNY Fredonia are challenged to find a way to encourage their students to achieve this level of participation. This challenge, coupled with that of trying to find a more effective way to teach business writing, provided the motivation for the current study.

Using a case study, Nwadike and Ekeanyanwu (2011) studied whether technology could enhance student performance in a speech communication class. They compared a traditionally taught course with a hybrid class, which, although presented online, retained some face-to-face teacher-student interaction. The traditional course involved lectures that used conventional materials such as blackboards, overheads, transparencies, videos, and handouts; no computers were used. The hybrid course also utilized lectures and face-to-face interactions but was conducted in a laboratory setting, used Blackboard (computer program), and involved the use of computers both in and out of the classroom but did not use a specific digital application targeted to a certain concept.

The results indicated that technology did not enhance performance, as there was no difference in the performance of students enrolled in the traditional class versus the hybrid class. Additionally, students in the hybrid class had mixed feelings about the technology, and some complained of technical problems or lack of technical support. The researchers concluded that learning is not a product of technology; rather, it results from the students' connectedness to the constructs of the learning process. 
Other research has focused on digital applications targeted toward writing. Sterkel, Johnson, and Sjogren (1986) focused on the effects of Writer's Workbench (computer program) on students' ability to write effective business communications. The results indicated that this computer application did not significantly improve grades during the first two semesters of the study; however, during the third semester, the experimental group demonstrated improvement in concreteness and conciseness. Sterkel et al. noted, however, that the improvement might have been the result of refinements made to the program. Nevertheless, that professors spent less time grading assignments for the experimental group was a notable finding. Additionally, the students were enthusiastic about use of the tool.

Because prior research has shown the importance of attitudes toward electronic writing tools, more recent research includes attitudes as a variable. Using a mixed-methods approach, Kay (2011) studied the effects of web-based learning tools (WBLTs) on teacher attitudes, student attitudes, and student performance in middle and secondary school science classrooms. The WBLTs allowed students to experiment with the concepts presented in class, using exercises, quizzes, and simulations targeted to the in-class presented focus. The results indicated that teachers thought that the WBLTs were well designed and engaging tools that supported learning, and both middle and secondary students felt that the WBLTs helped them to learn, even though some struggled when using them. Notably, WBLTs were found to lead to significant increases in student performance, and, overall, both teachers and students felt that WBLTs were a positive influence on the learning process.

\section{Purpose and Rationale}

The purpose of this study was to determine whether an electronic writing tool would lead to improvement in business writing skills. The results have the potential to provide professors of business communica- 
tions with an understanding of the impact of electronic writing tools on business writing proficiency.

\section{METHOD}

Two electronic writing tools were used for this study: (a) The Write Experience, a commercially available writing and evaluation tool (Cengage, n.d.b); and (b) Aplia, a commercially available textbook support tool that reinforces subject matter understanding through electronic quizzes and challenges (Cengage, n.d.a).

The Write Experience provides writing assignments for a business communications textbook, for which it serves as a companion, but the professor determines, on a chapter-by-chapter basis, which assignments are given to students (Cengage, n.d.b). Additionally, the professor can designate how many attempts students may make for a particular assignment, including the number of times that students can revise their work, in response to the tool's feedback and scoring. When students are satisfied with their writing or the number of allowable attempts has been reached, they submit their assignment to the professor. The professor grades the final submission using the department's approved writing rubric (Appendix A; State University of New York at Fredonia, 2010).

Aplia provides assessment materials, which function as a digital exam, for chapters of a business communications textbook for which it serves as a companion. Students review the chapter material and then take the assessment for that chapter. Similar to The Write Experience, the professor selects the content to be evaluated and then assigns dates for completion. When the assignment is complete, the assignment is scored by Aplia, and the professor retrieves the scores. Unlike The Write Experience, this tool focuses on writing theory content as opposed to writing practice (Cengage, n.d.a). 
Two sections of Business Communications 235 at SUNY Fredonia were selected for this study. Section A was taught with a traditional teaching pedagogy that included business writing instruction and out-of-class writing assignments that were evaluated by the professor, using the curriculum-approved rubric. Section B also was taught with traditional in-class pedagogy but two electronic writing tools were used to support the in-class work and out-of-class electronic writing assignments.

The demographics of the students who took the courses were largely traditional; virtually all students fell within the 19- to 21-year-old age bracket, and gender was equally distributed. Although no clear assessment was made of the students' computer skills, in general, the students demonstrated comfort with technology, as evidenced by their extensive use of the electronic learning management suite Angel, social media, and office applications.

The electronic writing assignments were scored using a 6-point Likert scale built into The Write Experience, with $1=$ highly inadequate communication and $6=$ highly effective communication. The assignments and scores were reviewed by the professor to identify any apparent aberrations in scoring as related to the curriculum-approved rubric as well as to determine the support needed by the student.

On the first day of class, the professors explained the study to the students and provided them with informed consent to participate in the research. A writing diagnostic assignment, which involved students' writing a memo to the professor about what they hoped to get from the class, was given. The students were instructed not to provide any identifying information on the memo. Students were asked to indicate, "You may NOT use my data as part of your study," if they did not wish to participate. A student was asked to collect the assignment, review the assignments to ensure that no names or other identifying information appeared on the memo, and place the assignments in a manila envelope labeled "Pre-Course Diagnostic: Section (A or B)." The envelope was 
sealed and given to the professor. Informed consents were included in the envelope.

Both envelopes were given to an administrative assistant, who removed and destroyed any assignments that indicated that they should not be used or that contained identifying information. The purpose of this second check was to ensure the confidentiality of the respondents. This activity resulted in a final sample of 58, as two of the 60 students opted out of the study. The administrative assistant coded the assignments as either Section A or Section B and then put all the assignments into one package and consecutively numbered them. The administrative assistant revealed the codes only after all scoring was completed. The assignments were then given to one professor, who scored them, using the School of Business-approved rubric. They were then provided to the other professor, who scored them independently, also using the curriculum-approved rubric. The resulting scores were maintained in electronic format by each professor until the data collection was complete.

At the conclusion of the semester, each professor administered another writing diagnostic assignment. Students were asked to write a memo to the professor about one great business communication tool that they learned to use during the semester. These data were managed in the same way as the pre-course data described above. Specifically, students were asked not to identify themselves, a student evaluated the documents to ensure that there were no identifying marks, and the documents were given to an administrative assistant, who reviewed them. Again, two of the 60 students opted out, for a final sample of 58. The administrative assistant coded and numbered the documents, which were then given to the first professor for evaluation. The results of each evaluation were recorded separately from the students' documents. The documents were then provided to the second professor for evaluation. Then both professors secured the codes from the administrative assistant and categorized the scores by sections. Data analysis was then conducted. 


\section{RESULTS}

To determine whether the students in the two groups were comparable in their baseline writing skills, their proficiency was calculated as the mean of their individual rubric scores, which ranged from 0 to 8 . The scores determined by each professor were averaged for each individual submission. Although variation was noted in terms of each individual professor's assignment of a rubric score within a dimension, the differences within dimensional scoring were never more than one degree; for example, while one professor might evaluate the dimension of "Format" as "Meets or Exceeds Standards," the other professor might evaluate that same dimension as "Approaches Standards." The entire section mean was then calculated. The mean for students in Section A was 5.02 and, for students in Section B, 5.52. A two-sample $t$-test yielded $p=.157$, indicating no significant difference between the scores of students in the two groups.

Mean scores were calculated again at the end of the course in the same manner as the pre-course analysis. The post-course mean score for students in Section A was 5.60. A two-sample $t$-test of the pre- and post-scores yielded $p=.126$, indicating no significant improvement in the mean score. The post-course mean score for students in Section B was 6.92. A two-sample $t$-test of the pre- and post-scores yielded $p=.000$, indicating significant improvement in the mean score. Finally, a twosample $t$-test used to compare the post-course mean scores of the two groups yielded $p=.000$, indicating a significant difference between the two groups.

\section{Discussion}

Students who used the electronic writing tools, in addition to participating in traditional pedagogy (Section B), demonstrated statistically significant improvement in business writing skills, both from pre- to post-test and as compared to students who participated only in the 
traditional pedagogy (Section A). Overall, the results suggest that the use of electronic business writing tools contributes to improvements in business writing proficiency. This finding supports the research of Kay (2011), who found that WBLTs were found to lead to significant increases in student performance, and that of Sterkel et al. (1984), who found that, with some refinements, a digital tool can lead to improvement in concreteness and conciseness. This finding, however, stands in contrast to that of Nwadike and Ekeanyanwu (2011), who concluded that learning is not a product of technology; rather, it results from the students' connectedness to the constructs of the learning process. Nevertheless, technology can enhance that connectedness. To this end, the Write Experience and Aplia are clearly targeted to writing outcomes and, as such, are aligned with learning constructs and the learning process.

\section{Limitations}

The study had several limitations, which need to be noted. The study relied on the implementation of curriculum by two separate professors, each with a unique teaching style. Further, although course objectives were the same for both sections, how these objectives were met by the professors was not standardized within the classroom setting. For example, the professor for Section B may have focused more on writing in class than did the professor for Section A. Additionally, the curriculum-approved writing rubric (Appendix A), used to evaluate the writing between sections was not tested for reliability prior to the study. Further, no training on the use of the rubric was conducted.

\section{RECOMMENDATIONS}

Despite the above noted limitations, the findings are worthy of consideration and further research. The first priority is to determine the reliability of the grading rubric used to measure the written communication. This could best be accomplished by attribute agreement analysis. 
Once the reliability of the rubric is established, future research should ensure the consistency of content delivery such that any post-course differences could be attributed to the electronic writing tools. To accomplish this, two sections of the Business Communications courses would be taught by the same professor in the same semester. Specifically, one section would be taught using traditional pedagogy and the other with the electronic writing tools. The investigators would then compare writing samples from students in the two sections. This configuration should be replicated for two sequential semesters and, in the same manner, by another instructor for two sections. This would yield a total of eight course sections, with a comparable number of students taking the course from one of two different professors and utilizing one of two different teaching methods. In all cases, however, the same writing rubric would be used.

The results of this more controlled study, with a larger overall sample size, should yield more robust results. For example, analysis could include cross-tabulations by instructor and method as well as by mean scores for each of the four measures on the rubric (format, organization, language, and punctuation). A larger sample also would allow the results to be segmented by such variables student major, class year, attendance, and participation (engagement) to gauge their effect on performance. By segregating all the variables that could affect overall student scores, the effectiveness of the electronic writing tools can be better captured.

\section{REFERENCES}

Arias, J. J., \& Walker, D. M. (2004, Fall). Additional evidence on the relationship between class size and student performance. Research in Economic Education, 311-329.

Cengage. (n.d.a). Aplia. Retrieved from http://www.cengage.com/ tlconnect/client/product/findProduct.do?productId=355 
Cengage. (n.d.b). Better writing. Better outcomes. Retrieved from http:// www.cengagesites.com/academic/? site $=4994 \& \operatorname{Sec} I D=3918$

Kay, R. (2011). Examining the effectiveness of web-based learning tools in middle and secondary school science classrooms. Interdisciplinary fournal of E-Learning and Learning Objects, 7, 359-374.

Nwadike, F. O., \& Ekeanyanwu, N. T. (2011). Teaching speech communication in a Black college: Does technology make a difference? USChina Education Review, B2, 195-202.

State University of New York at Fredonia. (2010). School of Business: Approved rubric for evaluation of business writing, Version 1.0. Fredonia, NY: Author.

Sterkel, K. S., Johnson, M. I., \& Sjogren, D. D. (1984). Textual analysis with computers to improve the writing skills of business communication students. The Journal of Business Communication, 23(1), 43-61. http:// dx.doi.org/10.1177/002194368602300104

\section{Web APPEndix}

A web appendix for this paper is available at:

http://dx.doi.org/10.15239/j.brcadvje.2014.02.01.wa01

\section{Citation Information}

Walters, Lisa M. and Susan McNamara. "The Effect of Electronic Writing Tools on Business Writing Proficiency" BRC fournal of Advances in Education 2, no. 1 (2014): 1-11. http://dx.doi.org/10.15239/ j.brcadvje.2014.02.01.ja01 